\title{
THREE-DIMENSIONAL CONSOLIDATION THEORY OF VERTICAL DRAIN BASED ON CONTINUOUS DRAINAGE BOUNDARY
}

\author{
Yi ZHANG ${ }^{1}$, Wenbing WU1,2, Guoxiong MEI'2, Longchen DUAN ${ }^{1 *}$ \\ ${ }^{1}$ Faculty of Engineering, China University of Geosciences, Wuhan, 430074, China \\ ${ }^{2}$ College of Civil Engineering and Architecture, Guangxi University, Nanning, 530004, China
}

Received 20 June 2018; accepted 19 November 2018

\begin{abstract}
To remedy the limitation that the conventional drainage boundary only considers two extreme cases of pervious and impervious boundaries, the consolidation theory of vertical drain is derived by applying the continuous drainage boundary, and its validity is also proven. Based on the obtained solutions, the excess pore water pressure and the average degree of consolidation under the continuous drainage boundary condition are analyzed, and the effect of the drainage capacity of the top surface, the smear effect and the well resistance on consolidation are explored. Furthermore, the practicality of this theory is also validated by the comparison with experimental data. Results confirm that the complete and continuous process of the ground top surface can be changed from no drainage to a complete drainage by adjusting the value of the interface parameter $b$. Higher value of the interface parameter $b$ means a stronger water permeability of the foundation, resulting in a faster dissipation of excess pore water pressure and a faster consolidation. Meanwhile, the vertical drainage of the vertical drain cannot be neglected in calculation even though vertical drains are based on a horizontal seepage. Moreover, the smear effect and the well resistance play an important role on consolidation.
\end{abstract}

Keywords: consolidation, vertical drain, continuous drainage boundary, interface parameter, smear effect, well resistance.

\section{Introduction}

Consolidation significantly influences soil strength and the stability of buildings (Gibson, 1958; Karlsson, Emdal, \& Dijkstra, 2016; Sales, Prezzi, Salgado, Choi, \& Lee, 2017). Accurate prediction of the consolidation of foundation soil and the settlement of buildings is of great significance to the construction, design and safety of engineering. With the rapid expansion of coastal land reclamation, properties, such as high moisture content and low permeability of dredger fills motivate the development of consolidation theories. In 1942, Carrillo established the expression of the relationship between the average consolidation degree of unidirectional seepage and the total average consolidation degree of multi-directional seepage, which provided a theoretical basis for simplifying the calculation of multidimensional consolidation (Carrillo, 1942). Thus, consolidation theory has been developed rapidly under the condition of equal strain hypothesis and free strain condition respectively (Barron, 1948; Yoshikuni \& Nakanodo, 1974; Hansbo, Jamiolkowski, \& Kok, 1981; Xie \& Zeng, 1989; Wang, Shen, Ho, \& Kim, 2013; Basack \& Nimbalkar, 2017; Geng \& Yu, 2017).
Many properties such as permeability coefficient and compression coefficient will be changed due to the disturbance of soil during the installation of vertical drains. Azari, Fatahi, and Khabbaz (2016) pointed out that the disturbance would lead to a reduction of OCR (over-consolidation ratio) and the strength of soil. Hence, the settlements of soil and the dissipation of excess pore water pressure were studied under five possible profiles of OCR in the smear and transition zones. Results show that the settlements of soil vary greatly under different OCR. The higher the OCR value of smear and transition zones is, the higher the creep limit strain is, and the faster the dissipation of excess pore water pressure is. Moreover, other researchers have taken the smear effect into the theory of vertical drain consolidation (Indraratna, Rujikiatkamjorn, \& Sathananthan, 2005; Rujikiatkamjorn \& Indraratna, 2009; Zhou \& Chai, 2017). During consolidation, vertical drains may be blocked by particles, resulting in a reduction of drainage capacity of vertical drains. Therefore, the analytical solutions which consider the well resistance have been obtained (Deng, Xie, Lu, Tao, \& Liu, 2013; Kim,

*Corresponding author. E-mail: 645812313@qq.com 
Hong, M. J. Lee, \& W. Lee, 2011). In addition, the research on the consolidation theory of vertical drain has also made considerable progress in the field of soil nonlinear ( $\mathrm{Lu}$, Wang, \& Sloan, 2015; Hu, Xia, Cui, Li, \& Xie, 2018; Karim \& Oka, 2010; Li, Xu, \& Xie, 2017) and non-Darcy seepage (Xie, K. Wang, \& Y. L. Wang, 2010; Taslimian, Noorzad, \& Javan, 2015).

The drainage capacity of boundary surface has a significant influence on consolidation calculation. For example, if a soil sample is placed in an impervious plastic bag, it cannot be consolidated no matter how long it takes and how much load applied. Several researchers proposed the semi-permeable boundary and studied the issue on this basis because the Terzaghi's boundary can only express the limit state which is completely permeable or completely impervious and is different from actual conditions (Wang, Sun, L. Z. Li, P. C. Li, \& Xu, 2017; Cai, Liang, Zheng, \& Pan, 2003; Sun, X. Y. Xie, \& K. H. Xie, 2003). However, the meaning of the semi-permeable boundary condition is unclear, because it cannot quantify the permeability of the boundary surface. Therefore, G. X. Mei, Xia, and L. Mei (2011) proposed the continuous drainage boundary and obtained corresponding analytical solutions. This theory overcomes the abovementioned shortcomings and thus has practical application value. Thus, the objective of this paper is to introduce the continuous drainage boundary to study the $3 \mathrm{D}$ consolidation behavior of vertical drain.

\section{Problem description}

Most analytical solutions of traditional consolidation theories are based on Terzaghi's boundary conditions and initial condition, which are as follows.

Initial condition:

$$
\left.u(t, z)\right|_{t=0}=p \text {. }
$$

Boundary conditions:

$$
\begin{aligned}
& \left.u(t, z)\right|_{z=0}=0, \\
& \left.\frac{\partial u}{\partial z}\right|_{z=h}=0 .
\end{aligned}
$$

Considering Eqn (1), when $z=0$, the following result can be obtained:

$$
u(0,0)=p .
$$

Considering Eqn (2), when $t=0$, the following result can be obtained:

$$
u(0,0)=0 .
$$

By comparing Eqns (4) and (5), we can obtain

$$
\left\{\begin{array}{l}
u(0,0)=p \\
u(0,0)=0
\end{array} \rightarrow\right. \text { contradictory . }
$$

Traditional consolidation theory regards the top surface as the extreme drainage state, which is contrary to reality. The drainage boundary in reality should be in a state between the two extreme cases of completely pervious and impervious boundaries.
Considering the above contradictions and combining the following characteristics of the drainage boundary:

a) at the initial time $(t=0)$, the excess pore water pressure at any depth has not been dissipated, that is, $u(0, z)=p$

b) as time goes by, the excess pore water pressure on the boundary monotonously decreases;

c) when time is long enough, the excess pore water pressure is completely dissipated, that is, when $t \rightarrow \infty, u=0$.

Mei et al. (2011) proposed the continuous drainage boundary condition related to the load and time as follows:

$$
u(t, 0)=p e^{-b t} .
$$

In this equation, $u(t, 0)$ is the excess pore pressure at the top boundary of any time; $p$ is instantaneous constant load; $b$ is the interface parameter which reflects the drainage performance of the boundary. The interface parameter can be obtained by experimental simulation or engineering measurement inversion. Based on Eqn (6), when $b \rightarrow \infty$, $u(t, 0)=0$. The continuous drainage boundary can then be degenerated into the complete drainage boundary.

The abovementioned contradictions also exist for the 3D consolidation theory of vertical drain under instantaneous constant load. Therefore, the continuous drainage boundary condition is also suitable for the $3 \mathrm{D}$ consolidation theory of vertical drain.

\section{Mathematical formulation}

\subsection{Assumptions}

Taking single well as the research subject, the model of vertical-drain foundation is illustrated in Figure 1, where $p$ is the instantaneous constant additional load; $r_{w}, r_{s}$, and $r_{e}$ are the vertical-drain radius, the maximum radius of the smear area, and the maximum influence radius of vertical drain, respectively; $k_{h}$ and $k_{v}$ are the radial and vertical permeability coefficients of the dredger fill, respectively; $k_{s}$ and $k_{w}$ are the permeability coefficients of the smear area and the vertical drain respectively, which can be used to characterize the smear effect and the well resistance effect of the vertical drain; $H$ is the depth of the vertical drain. Consolidation of vertical drain can be simplified as a cylindrical axis symmetric consolidation problem with vertical drain as the drainage center, as shown in Figure 1.

To simplify the derivation process, the following assumptions are made:

a) equal-strain condition is applicable;

b) seepage obeys Darcy's law;

c) at any depth, the amount of water flowing into the pile from the soil is equal to the amount of water discharged from the pile;

d) the soil is assumed to be homogeneous, and permeability coefficients and the compression coefficient remain unchanged during the consolidation; 


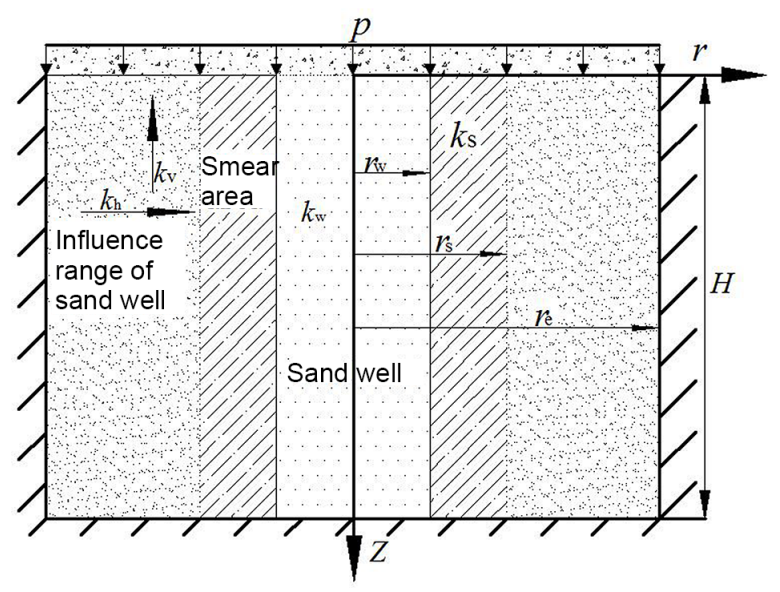

Figure 1. Vertical-drain foundation model

e) other properties of soil in the smear area are the same as in natural foundation, except for the horizontal permeability coefficient;

f) effects of rainfall and temperature are ignored.

The above assumptions may not be exact for some cases, especially the assumption d). Because the permeability coefficient will diminish if soil is blocked by particles, and the compression modulus will increase due to the effect of pre-consolidation pressure. However, according to Ho, Fatahi, and Khabbaz $(2015,2016)$, it may be acceptable to assume that these parameters remain constant during the transient process for a particular stress increment.

\subsection{Derivation of control equation}

(1) Balanced equation

The soil is considered to have no lateral deformation under the assumption of equal strain, and the additional load is a uniform instantaneous constant load.

$$
\begin{aligned}
& \frac{\partial \varepsilon_{v}}{\partial t}=-\frac{1}{E_{s}} \frac{\partial\left(\sigma_{0}-\overline{u_{r}}\right)}{\partial t}=-\frac{1}{E_{s}} \frac{\partial \overline{u_{r}}}{\partial t}, \\
& \overline{u_{r}}=\frac{1}{\pi\left(r_{e}^{2}-r_{w}^{2}\right)} \int_{r_{w}}^{r_{e}} 2 \pi r u_{r}(r, z, t) d r .
\end{aligned}
$$

In Eqns (7) and (8), $\sigma_{0}$ is the total stress, $\sigma_{0}=p ; \varepsilon_{v}$ is the volumetric strain which is equal to the vertical strain; $u_{r}$ and $\bar{u}_{r}$ are respectively the excess pore water pressure and the average excess pore water pressure at any point in the soil; $E_{\mathrm{s}}$ is the modulus of compression of the foundation soil.

\section{(2) Seepage continuity equation}

A small circle with a height of $\mathrm{d} z$ and a thickness of $\mathrm{d} r$ is taken out from the vertical drain foundation model, as shown in Figure 2.

Seepage occurs not only in the radial direction but also in the vertical direction. The flow velocities from the inner and upper surface of the flow unit model are thus assumed to be $v_{h}$ and $v_{v}$, respectively. Considering the continuity of the water flow, the velocities of water flowing

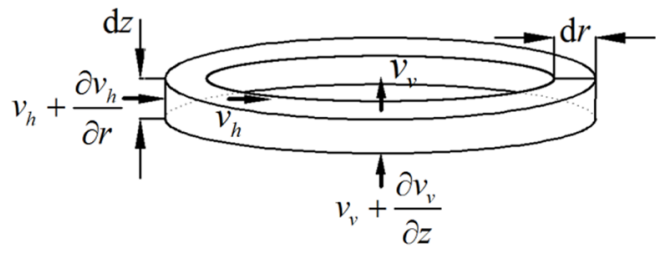

Figure 2. Flow unit model

in from outside and bottom are $v_{h}+\frac{\partial v_{h}}{\partial r}$ and $v_{v}+\frac{\partial v_{v}}{\partial z}$,
respectively.

The change rate of water inside the small ring is thus expressed as follows:

$$
\begin{aligned}
\frac{\partial Q}{\partial t}= & {\left[v_{v}-\left(v_{v}+\frac{\partial v_{v}}{\partial z} d z\right)\right] \cdot\left[\pi(r+d r)^{2}-\pi r^{2}\right]+} \\
& \left\{v_{h} \cdot(2 \pi r)-\left(v_{h}+\frac{\partial v_{h}}{\partial r} d r\right)[2 \pi(r+d r)]\right\} d z .
\end{aligned}
$$

The volume change rate of the small ring is expressed as follows:

$$
\frac{\partial V}{\partial t}=\pi\left[(r+d r)^{2}-r^{2}\right] d z \cdot \frac{\partial \varepsilon_{v}}{\partial t} .
$$

Because the rate of flow change in the small circle equals to the bulk change rate, $\frac{\partial V}{\partial t}=\frac{\partial Q}{\partial t}$. Take in and omit the higher-order trace and simplify to obtain the following equation:

$$
-\frac{1}{r}\left(v_{h}+r \frac{\partial v_{h}}{\partial r}\right)-\frac{\partial v_{v}}{\partial z}=\frac{\partial \varepsilon_{v}}{\partial t} .
$$

According to Darcy's law, the water flow velocity can be expressed as follows:

$$
\left\{\begin{array}{l}
v_{h}=\frac{k_{h}}{\gamma_{w}} \frac{\partial u_{r}}{\partial r} \\
v_{v}=\frac{k_{v}}{\gamma_{w}} \frac{\partial \overline{u_{r}}}{\partial z}
\end{array} .\right.
$$

Substituting Eqn (12) into Eqn (11) yields

$$
\frac{1}{r} \frac{k_{h}}{\gamma_{w}} \frac{\partial u_{r}}{\partial r}+\frac{k_{h}}{\gamma_{w}} \frac{\partial^{2} u_{r}}{\partial r^{2}}+\frac{k_{v}}{\gamma_{w}} \frac{\partial^{2} \overline{u_{r}}}{\partial z^{2}}=-\frac{\partial \varepsilon_{v}}{\partial t} .
$$

To avoid a piecewise function caused by the difference of the permeability coefficient between the smear area and the non-smear area, Eqn (13) can be expressed as:

$$
\frac{1}{r} \frac{\partial}{\partial r}\left[\frac{k_{r}(r)}{\gamma_{w}} r \frac{\partial u_{r}}{\partial r}\right]+\frac{k_{v}}{\gamma_{w}} \frac{\partial^{2} \overline{u_{r}}}{\partial z^{2}}=-\frac{\partial \varepsilon_{v}}{\partial t},
$$

where

$$
\begin{aligned}
& k_{r}(r)=k_{h} f(r), \\
& f(r)= \begin{cases}\frac{k_{s}}{k_{h}}=\alpha & r_{w}<r<r_{s} \\
1 & r_{s}<r<r_{e}\end{cases}
\end{aligned}
$$


In Eqn (16), $\alpha$ is a constant. According to the assumption c), the following equation can be obtained:

$$
\left.\left[2 \pi r d z \frac{k_{r}(r)}{\gamma_{w}} \frac{\partial u_{r}}{\partial r}\right]\right|_{r=r_{w}}=-\pi r_{w}^{2} d z \frac{k_{w}}{\gamma_{w}} \frac{\partial^{2} u_{w}}{\partial z^{2}} .
$$

\subsection{Analytical solution}

As described in Section 2.2, the following main equations can be summarized:

$$
\begin{aligned}
& \int \frac{\partial \varepsilon_{v}}{\partial t}=-\frac{1}{E_{s}} \frac{\partial\left(\sigma_{0}-\overline{u_{r}}\right)}{\partial t}=-\frac{1}{E_{s}} \frac{\partial \overline{u_{r}}}{\partial t} \\
& \overline{u_{r}}=\frac{1}{\pi\left(r_{e}^{2}-r_{w}^{2}\right)} \int_{r_{w}}^{r_{e}} 2 \pi r u_{r}(r, z, t) d r \\
& \frac{1}{r} \frac{\partial}{\partial r}\left[\frac{k_{r}(r)}{\gamma_{w}} r \frac{\partial u_{r}}{\partial r}\right]+\frac{k_{v}}{\gamma_{w}} \frac{\partial^{2} \overline{u_{r}}}{\partial z^{2}}=-\frac{\partial \varepsilon_{v}}{\partial t} \\
& {\left[\left.\left\lfloor 2 \pi r d z \frac{k_{r}(r)}{\gamma_{w}} \frac{\partial u_{r}}{\partial r}\right]\right|_{r=r_{w}}=-\pi r_{w}^{2} d z \frac{k_{w}}{\gamma_{w}} \frac{\partial^{2} u_{w}}{\partial z^{2}},\right.}
\end{aligned}
$$

where $u_{w}$ is the excess pore water pressure in vertical drains.

Solving conditions are as follows:

Initial condition:

$$
\left.\overline{u_{r}}\right|_{t=0}=\left.u_{w}(z, t)\right|_{t=0}=p,
$$

boundary conditions:

$$
\begin{cases}\left.\frac{\partial u_{r}}{\partial r}\right|_{r=r_{e}}=0 & \text { (Impermeable lateral boundary) } \\ \left.u_{w}\right|_{z=0}=p e^{-b t} & \text { (Continuous top surface) } \\ \left.\frac{\partial u_{w}}{\partial z}\right|_{z=H}=0 & \text { (Impermeable bottomboundary) } \\ \left.u_{r}\right|_{r=r_{w}}=u_{w} & \text { (Pore pressure continuous) } .\end{cases}
$$

By integrating Eqn (14) twice about $r$, the boundary condition is replaced, and the following results can be obtained:

$$
u_{r}=u_{w}+\frac{\gamma_{w}}{2 k_{h}}\left(\frac{\partial \varepsilon_{v}}{\partial t}+\frac{k_{v}}{\gamma_{w}} \frac{\partial^{2} \overline{u_{r}}}{\partial z^{2}}\right)\left[r_{e}^{2} A_{0}(r)-B_{0}(r)\right]
$$

In this equation $\left\{\begin{array}{l}A_{0}(r)=\int_{r_{w}}^{r} \frac{d \tau}{\tau f(\tau)} \\ B_{0}(r)=\int_{r_{w}}^{r} \frac{\tau d \tau}{f(\tau)}\end{array}\right.$.

Substituting Eqn (18) in Eqn (8) yields:

$$
\overline{u_{r}}=u_{w}+\frac{\gamma_{w} r_{e}^{2} J}{2 k_{h}}\left(\frac{\partial \varepsilon_{v}}{\partial t}+\frac{k_{v}}{\gamma_{w}} \frac{\partial^{2} \overline{u_{r}}}{\partial z^{2}}\right)
$$

where $J$ is a constant, i.e. $J=\frac{n^{2}}{n^{2}-1}\left[\left(\frac{k_{h}}{k_{s}}-1\right) \ln s+\ln n+\right.$ $\left.\frac{\left(s^{2}-3\right)\left(s^{2}-1\right)}{4 n^{2}} \frac{k_{h}}{k_{s}}-\frac{\left(s^{2}-3\right)\left(s^{2}-1\right)}{4 n^{2}}\right]$.
In the equation, $s=\frac{r_{s}}{r_{w}}$ indicates the relative size of the smear area range; $n=\frac{r_{e}}{r_{w}}$ is the ratio of the well diameter which indicates the relative size of the vertical drain.

Solving the derivative of $r$ for Eqn (18) and then substituting it into Eqn (17) yield:

$$
\frac{k_{w}}{\gamma_{w}} \frac{\partial^{2} u_{w}}{\partial z^{2}}=-\left(n^{2}-1\right)\left(\frac{\partial \varepsilon_{v}}{\partial t}+\frac{k_{v}}{\gamma_{w}} \frac{\partial^{2} \overline{u_{r}}}{\partial z^{2}}\right) \text {. }
$$

Substituting Eqn (20) into Eqn (19) yields:

$$
\overline{u_{r}}=u_{w}+B \frac{\partial^{2} u_{w}}{\partial z^{2}} \text {. }
$$

Substituting Eqn (7) and Eqn (21) into Eqn (19) to eliminate $\frac{\partial \varepsilon_{v}}{\partial t}$ and $\overline{u_{r}}$ respectively, and the equation can be expressed by $u_{w}$ as Eqn (22):

$$
A \frac{\partial^{4} u_{w}}{\partial z^{4}}+B \frac{\partial^{3} u_{w}}{\partial z^{2} \partial t}+C \frac{\partial^{2} u_{w}}{\partial z^{2}}+\frac{\partial u_{w}}{\partial t}=0,
$$

where $A=\frac{r_{e}^{2} J k_{w} k_{v} E_{s}}{2\left(n^{2}-1\right) k_{h} \gamma_{w}}, B=-\frac{r_{e}^{2} J k_{w}}{2\left(n^{2}-1\right) k_{h}}$, $C=-\frac{k_{v} E_{s}\left(n^{2}-1\right)+k_{w} E_{s}}{\left(n^{2}-1\right) \gamma_{w}}$, are constants related to soil parameters.

Eqn (22) is now solved under the initial condition (A) and the boundary conditions (C) and (D).

Let

$$
u_{w}(z, t)=v(z, t)+p e^{-b t} .
$$

The solving conditions are expressed homogeneously as follows:

Initial condition:

$$
v(z, 0)=0,
$$

boundary conditions:

$$
\left\{\begin{array}{l}
v(0, t)=0 \\
\left.\frac{\partial v}{\partial z}\right|_{z=H}=0 .
\end{array}\right.
$$

According to the boundary conditions, the eigen function method is used:

$$
v(z, t)=\sum_{m=0}^{\infty} g_{m}(t) \cdot \sin \left(\frac{M}{H} z\right),
$$

where $M=\frac{2 m+1}{2} \pi, m=0,1,2 \ldots$

By substituting Eqn (23) into Eqn (22), we can obtain

$$
A \frac{\partial^{4} v}{\partial z^{4}}+B \frac{\partial^{3} v}{\partial z^{2} \partial t}+C \frac{\partial^{2} v}{\partial z^{2}}+\frac{\partial v}{\partial t}=p b e^{-b t} .
$$

Substituting Eqn (24) into Eqn (25), according to the Fourier transform, yields: 


$$
\begin{aligned}
& \sum_{m=0}^{\infty}\left[g_{m}^{\prime}(t)+\frac{A\left(\frac{M}{H}\right)^{4}-C\left(\frac{M}{H}\right)^{2}}{1-B\left(\frac{M}{H}\right)^{2}} g_{m}(t)\right] \cdot \sin \left(\frac{M}{H} z\right)= \\
& \sum_{m=0}^{\infty}\left[\frac{1}{1-B\left(\frac{M}{H}\right)^{2}} \frac{2 p b e^{-b t}}{M}\right] \cdot \sin \left(\frac{M}{H} z\right) .
\end{aligned}
$$

In other words,

$$
\sum_{m=0}^{\infty}\left[g_{m}^{\prime}(t)+Y \cdot g_{m}(t)\right]=\sum_{m=0}^{\infty} N \cdot p e^{-b t}
$$

where $Y=\frac{A\left(\frac{M}{H}\right)^{4}-C\left(\frac{M}{H}\right)^{2}}{1-B\left(\frac{M}{H}\right)^{2}}$ and $N=\frac{1}{1-B\left(\frac{M}{H}\right)^{2}} \frac{2 b}{M}$.

By solving Eqn (27) according to the initial condition (A1), $g_{m}(t)=\sum_{m=0}^{\infty} \frac{N p}{Y-b}\left(e^{-b t}-e^{-Y t}\right)$ can be obtained. By substituting such equation into Eqn (24), the following equation is obtained:

$$
v(z, t)=\sum_{m=0}^{\infty} \frac{N p}{Y-b}\left(e^{-b t}-e^{-Y t}\right) \sin \left(\frac{M}{H} z\right) .
$$

By substituting the above equation into Eqn (23), the following equation can be obtained:

$$
u_{w}(z, t)=p e^{-b t}+\sum_{m=0}^{\infty} \frac{N p}{Y-b}\left(e^{-b t}-e^{-Y t}\right) \sin \left(\frac{M}{H} z\right),
$$

where $u_{w}$ is the excess pore water pressure at any time in the vertical drain at any depth.

By substituting Eqn (28), Eqn (21), and Eqn (19) into Eqn (18), the excess pore water pressure at any time and any position in the foundation can be obtained as:

$$
\begin{aligned}
u_{r}(z, r, t)= & p e^{-b t}+ \\
& \sum_{m=0}^{\infty}\left\{1-\frac{\left[r_{e}^{2} A_{0}(r)-B_{0}(r)\right] B}{r_{e}^{2} J}\left(\frac{M}{H}\right)^{2}\right\} . \\
& \frac{N p}{Y-b}\left(e^{-b t}-e^{-Y t}\right) \sin \left(\frac{M}{H} z\right)
\end{aligned}
$$

combining Eqns (21) and (29) yields

$$
\begin{aligned}
\overline{u_{r}}(z, t)= & p e^{-b t}+ \\
& \sum_{m=0}^{\infty} \frac{2 p}{M} \frac{b}{Y-b}\left(e^{-b t}-e^{-Y t}\right) \sin \left(\frac{M}{H} z\right) .
\end{aligned}
$$

The formula of the average consolidation degree is calculated based on strain. That is:

$$
\bar{U}=\frac{\sigma_{0}-\bar{u}}{\sigma_{0}}=1-\frac{\frac{1}{H} \int_{0}^{H \overline{u_{r}}} d z}{p} .
$$

By substituting Eqn (28) into Eqn (21) and then substituting the result into Eqn (30), the expression of the average consolidation degree under the continuous boundary conditions can be obtained as follows:

$$
\bar{U}=1-e^{-b t}-\sum_{m=0}^{\infty} \frac{1}{M^{2}} \frac{2 b\left(e^{-b t}-e^{-Y t}\right)}{Y-b} .
$$

Furthermore, the settlement could be expressed as the following equation,

$$
\begin{aligned}
S_{t}= & \int_{0}^{H} \varepsilon_{z} d z=\int_{0}^{H} \frac{\sigma_{0}-\bar{u}}{E_{s}} d z= \\
& \frac{H}{E_{s}} p-\frac{1}{E_{s}} \int_{0}^{H-} \overline{u_{r}} d z= \\
& \frac{H p}{E_{s}}\left\{\left(1-e^{-b t}\right)-\sum_{m=0}^{\infty} \frac{2 b}{M^{2}} \cdot \frac{\left(e^{-b t}-e^{-Y t}\right)}{Y-b}\right\} .
\end{aligned}
$$

\section{Validation of the solution}

The solution of the average consolidation degree under the continuous boundary condition is degraded and then compared with the existing results to verify the accuracy of the results.

First, let $b \rightarrow+\infty$ which means that the top surface is completely permeable. The result is then obtained as follows:

$$
\bar{U}=1-\sum_{m=0}^{\infty} \frac{2}{M^{2}} e^{-Y t} .
$$

This equation is consistent with the result obtained by Zhang, Xie, and Wang (2006).

The vertical permeability coefficient $k_{v}=0$ is then further made. The vertical drain is considered to have no vertical drain, which means only the radial drainage is considered. Substituting $k_{v}=0$ into Eqn (33), we can obtain:

$$
\bar{U}=1-\sum_{m=0}^{\infty} \frac{2}{M^{2}} e^{-\alpha t},
$$

where

$\alpha=\frac{\frac{2 E_{s} k_{h}}{\gamma_{w} J r_{e}^{2}}\left(\frac{M}{H}\right)^{2}}{\frac{2\left(n^{2}-1\right) k_{h}}{r_{e}^{2} J k_{w}}+\left(\frac{M}{H}\right)^{2}}$. This equation is consistent with the result obtained by Xie and Zeng (1989).

The curves are drawn as shown in Figure 3 according to the analytical solution to verify the accuracy of the results, and parameters used in curves are obtained from a coastal reclamation project in Cangnan County of Zhejiang Province, China, as shown in Table 1.

The average consolidation degree under the continuous boundary conditions is degraded, and the consolidation degree curves with time are drawn according to the parameters in Table 1. The curves obtained from Zhang, Xie, and Wang (2006) and Xie and Zeng (1989) are compared to verify the accuracy of the analytical solution, as shown in Figure 3. 
Table 1. Physical parameters of the soil

\begin{tabular}{|c|c|c|c|c|c|c|c|c|}
\hline \multirow{2}{*}{$\begin{array}{c}\text { Depth } \\
H / \mathrm{m}\end{array}$} & \multicolumn{4}{|c|}{ Permeability coefficient $k /(\mathrm{m} / \mathrm{d})$} & \multirow{3}{*}{$E_{s} / \mathrm{kPa}$} & \multicolumn{3}{|c|}{ Radius $r / \mathrm{m}$} \\
\cline { 2 - 6 } \cline { 7 - 9 } & $k_{h}$ & $k_{v}$ & $k_{s}$ & $k_{w}$ & & $r_{e}$ & $r_{s}$ & $r_{w}$ \\
\hline 10 & $4.32 \times 10^{-4}$ & $2.2 \times 10^{-4}$ & $4.33 \times 10^{-5}$ & 1.08 & 2000 & 2.5 & 1 & 0.25 \\
\hline
\end{tabular}

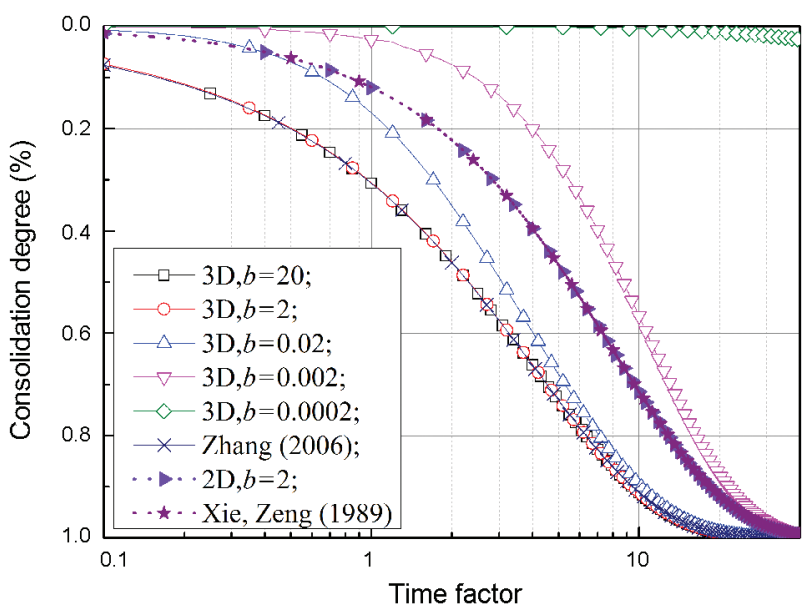

Figure 3. Verified curves of the consolidation degree

Figure 3 depicts the variation of consolidation degree versus the time factor. The solid lines consider both radial and vertical drainage, but the dot lines only consider the radial drainage, i.e. $k_{v}=0$. It can be seen that in the three-dimensional consolidation, when $b=0.0002$, the consolidation degree is almost zero. With the increasing of $b$, the consolidation rate increases, and the consolidation curve is gradually getting close to that of Zhang's, Xie, and Wang's (Zhang, Xie, \& Wang, 2006). When $b=2$, they are almost identical. When $b$ continues to increase, reaching 20 , the consolidation rate is not significantly accelerated, the variation of the consolidation versus time is almost the same as the curve of $b=2$. Furthermore, in the twodimensional consolidation, i.e. $k_{v}=0$, the consolidation curve of $b=2$ coincides with that of Xie and Zeng (1989). So, we can conclude that the top of the ground is completely permeable when $b=2$. Meanwhile, the consolidation model under the continuous drainage boundary condition is verified to be rational.

\section{Parametric study}

\subsection{Analysis of excess pore water pressure}

According to Eqn (30) and the parameters in Table 1, the variation curves of the excess pore pressure with depth under different influence factors are drawn, as shown in Figures 4 and 5 .

The solid and dashed lines in Figure 4 respectively represent the relationship between the excess pore water pressure at $1 \mathrm{~m}$ and $2 \mathrm{~m}$ from the vertical drain center and the different values of top surface seepage capacity. The Figure 4 shows that: (1) A smaller interface parameter $b$ leads to greater excess pore water pressure in the foundation regardless of whether lines are solid or dashed. Because

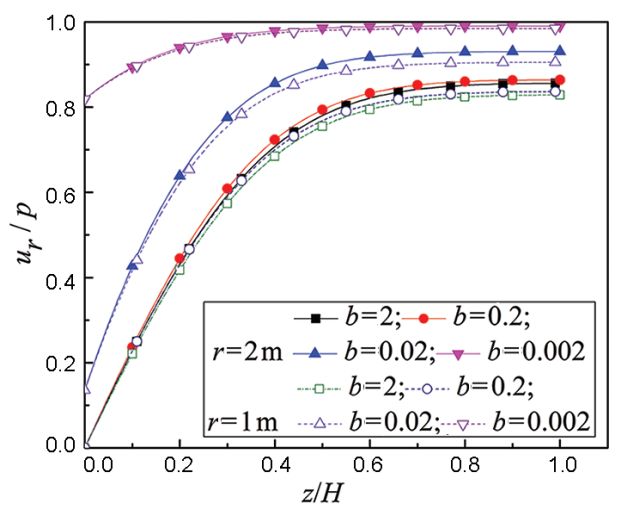

Figure 4. Relationship between excess pore water pressure and depth at different horizontal locations and top water drainage capacity

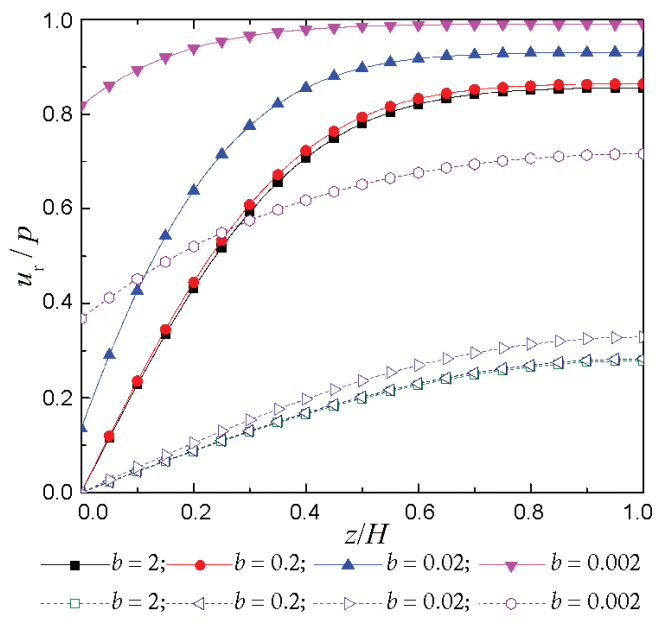

Figure 5. Relationship between excess pore water pressure and depth at different consolidation times and top water drainage capacities, The solid lines and dashed lines represent $T_{h}=1.4$ and $T_{h}=7$, respectively

$b$ characterizes the discharge capacity of the top surface, a smaller $b$ means a lower discharge capacity of the top surface and thus slower dissipation of excess pore water pressure. (2) Under the condition where consolidation time factor $T_{h}=1.4$ (equivalent to $t=100 \mathrm{~d}$ ), the initial excess pore pressure is 0 when $b$ is relatively large, such as $b \geq 0.2$. The pore pressure can rapidly dissipate because of the strong drainage capacity of the top surface. This result is the same as that of the conventional complete permeable boundary condition. When $b$ is relatively small, such as $b \leq 0.02$, the values of the excess pore pressure in the foundation top surface are not 0 . This result shows that the excess pore water pressure also exists on the foundation top surface. When $b=0.002$, the excess pore water pres- 
sure is close to the additional load $p$. That is, the pore pressure dissipates very little. The reason is that the foundation top surface is no longer a traditional complete drainage condition; rather it is in a weak permeable state. The dissipation of the excess pore water pressure on the top surface is therefore negligible at $T_{h}=1.4$. This phenomenon cannot be realized in the traditional consolidation theory of vertical drain. Therefore, by changing the interface parameter $b$, an entire continuous process can be realized from completely permeable to completely impermeable on the foundation top surface. This condition compensates for the limitation of the traditional consolidation theory which can only express the extreme conditions of completely permeable and impermeable water. (3) With decreasing $b$, the difference of the excess pore water pressure between the top and bottom of the foundation becomes increasingly smaller. The reason is that the discharge capacity of the top surface is strong but the bottom surface is undrained. A large $b$ makes a difference on the excess pore water pressure at the top and bottom. When $b$ is small, such as $b=0.002$, the discharge capacity of the top surface is slightly different from that of the bottom. The excess pore water pressure is therefore not significantly different. (4) Comparison of the solid and dashed lines reveals that the excess pore pressure at $r=1 \mathrm{~m}$ is smaller than that at $r=2 \mathrm{~m}$, because the nearer it is to the center of the vertical drain, the faster the drainage (i.e., the faster the pore pressure dissipates).

The solid and dashed lines in Figure 5 represent the relationship between excess pore water pressure and depth at different consolidation times. As shown in Figure 5, (1) the excess pore water pressure increases with decreasing interface parameter $b$; (2) for same $b$, the excess pore water pressure at $T_{h}=7$ (equivalent to $t=500 \mathrm{~d}$ ) is less than that at $T_{h}=1.4 ;(3)$ at $b=0.02$, the excess pore water pressure at the foundation top surface is not zero when $T_{h}=1.4$, but it is zero when $T_{h}=7$. The reason is that although the water permeability of the top surface is the same, over time, the excess pore water pressure at the top surface gradually dissipates to zero. It proves that the excess pore water pressure is related to time and the interface parameter $b$. Therefore, the excess pore water pressure at the top of ground is not always zero, but variable at different times. This result may be more consistent with the actual situation.

\subsection{Analysis of average consolidation degree}

According to Eqn (33) and the parameters in Table 1, the variation curves of the average degree of consolidation with time factor under different influencing factors (such as calculation method, interface parameters, smear area range, permeability coefficient, etc.) are drawn, as follows.

Figure 6 shows two curves of the relationship between the consolidation degree and time, obtained by two different methods. The dashed line is depicted based on Carrillo's (1942) method, which was previously used to calculate the vertical drain consolidation degree. The solid line is obtained by the method of radial-vertical coupling.

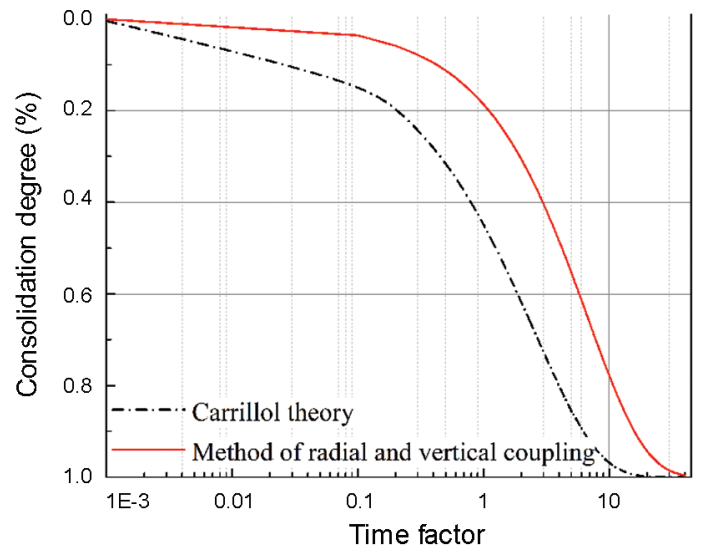

Figure 6. Comparison between Carrillo's (1942) method and this study

According to the figure, the results obtained by these two methods are different. That's because the Carrillo's (1942) method is a simplification, which separately calculates the radial consolidation and vertical consolidation. Then, the radial and vertical consolidation degrees are combined according to Eqn (37):

$$
\bar{U}=1-\left(1-\overline{U_{r}}\right)\left(1-\overline{U_{z}}\right),
$$

where $\overline{U_{r}}$ and $\overline{U_{z}}$ are consolidation degree of radial and vertical, respectively.

However, this approach may overestimate the consolidation rate. When the radial consolidation degree is calculated, the additional load $p$ only contributes to the radial drainage consolidation. Similarly, additional load $p$ fully contributes to vertical drain consolidation in the calculation of one-dimensional vertical consolidation. But in fact, the surcharge $p$ acts on both radial and vertical seepage. Therefore, the curves of consolidation show a difference, and using the radial-vertical coupling method is more reasonable to predict the consolidation.

As shown in Figure 7: (1) The average consolidation degree of the foundation is different when $b$ changes. The consolidation degree curves are considerably moved back with decreased $b$, i.e., a longer time is highly required with the same consolidation. The drainage capacity of the top surface significantly affects the consolidation speed. The complete permeable boundary proposed by the traditional consolidation theory may therefore overestimate the discharge and consolidation capacity of the foundation. (2) Comparison of the solid and dashed lines (i.e. 2D and $3 \mathrm{D}$ consolidation curves) reveals that although the consolidation of vertical drain is mainly based on radial drainage, a significant difference still exists between the $2 \mathrm{D}$ consolidation considering radial drainage and the 3D consolidation considering radial and vertical drain simultaneously. Under 3D consolidation, the $b=0.02$ (incomplete drainage) scenario is faster than the $b=2$ (fully drained) scenario under $2 \mathrm{D}$ conditions. Therefore, in actual engineering calculation, the vertical discharge capacity of vertical drain cannot be ignored. 


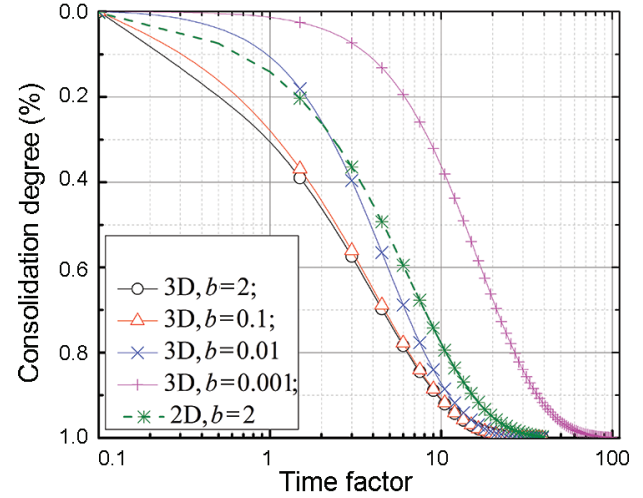

Figure 7. Relationship between consolidation degree and time under different drainage conditions of the foundation top surface, The solid lines and the dashed line represent the results of considering and not considering the top drainage

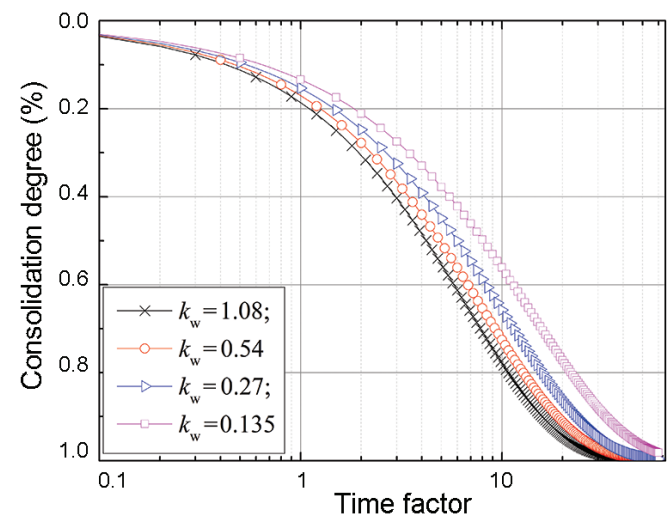

Figure 8. Influence of well resistance on consolidation degree

From Figure 8, it can be seen that the consolidation becomes slower with the decrease of the permeability coefficient of the vertical drain, so the drainage capacity of the vertical drain has a significant effect on the consolidation.

In Figure 9, when $k_{h} / k_{s}=1$, there is no smear effect. With the increase of $k_{h} / k_{s}$ (i.e. the permeability coefficient of the soil in smear area gradually decreases), the consolidation curve moves backward. That is, the consolidation speed slows down. It can be seen that the permeability of the smear area soil has a significant effect on the consolidation.

The solid and dashed lines in Figure 10 represent the effect of the smear area range on the average consolidation degree under the condition of complete and incomplete permeability of the top surface, respectively. As shown in Figure 10, the consolidation is significantly accelerated with decreased influence radius of the smear area regardless of the drainage capacity of the top surface.

The extent and permeability of the smear zone have a significant influence on the consolidation progress. In realistic engineering, the key issue is how to acquire values of the extent and the permeability, which is crucial to using the radial-vertical coupling method predict settlements accurately. Parsa-Pajouh, Fatahi, Vincent, and Khabbaz (2014a, 2014b) applied a developed FLAC code and adopted the proposed back calculation procedure to

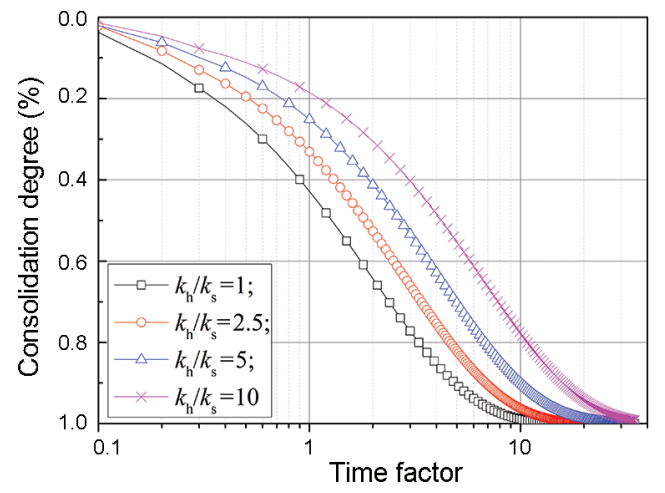

Figure 9. Effect of permeability coefficient of smear area on degree of consolidation

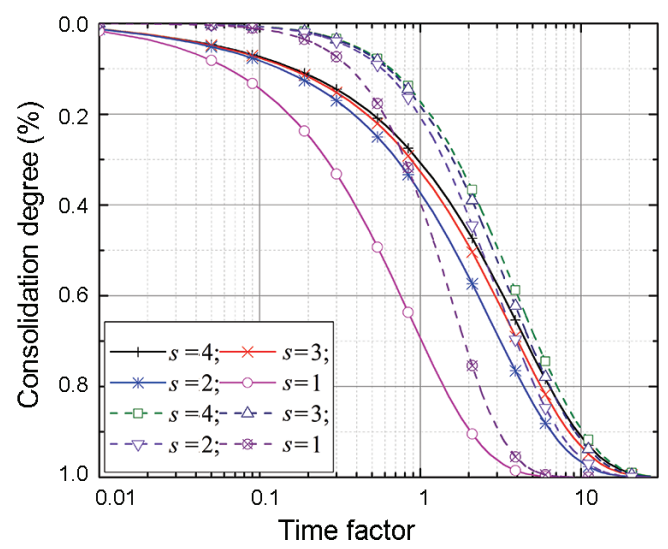

Figure 10. Influence of the smear effect on the consolidation degree. The solid lines and dashed lines represent $b=2$ and $b=0.02$, respectively

predict smear zone properties. This method provides an economic and practical approach for designers to obtain the permeability and extent of the smear zone in the early loading stages, which can be applied in the actual engineering calculation.

In Figure 11, the realistic well is assumed to be $b=0.02$, and other parameters are shown in Table 1. Well resistance means that the permeability coefficient of the vertical drain is $0.1 k_{\mathrm{w}}, k_{h}=k_{s}, b=0.02$, and other parameters are shown in Table 1 . Smear suggests that the permeability coefficient of the vertical drain is infinite, and it is 100 times as much as $k_{w}$ in Table $1, b=0.02$, but $k_{h}=k_{s}$. Ideal well is the condition in which there is neither well resistance nor smear, and $b=2$. As shown in Figure 11, the existence of the smear area significantly influences the consolidation of the ground. The consolidation degree curves of the ideal well and the realistic well are also considerably different as influences of the top drainage capacity, well resistance and the smear zone. Therefore, reducing the disturbance to the well wall during PVDs installation is appropriate.

In engineering practice, a rapid loading rate may result in ground failures when the ground soil is not sufficiently consolidated. Therefore, it is very important to accurately predict the process of consolidation. In the traditional theory of consolidation, top surface is considered completely 


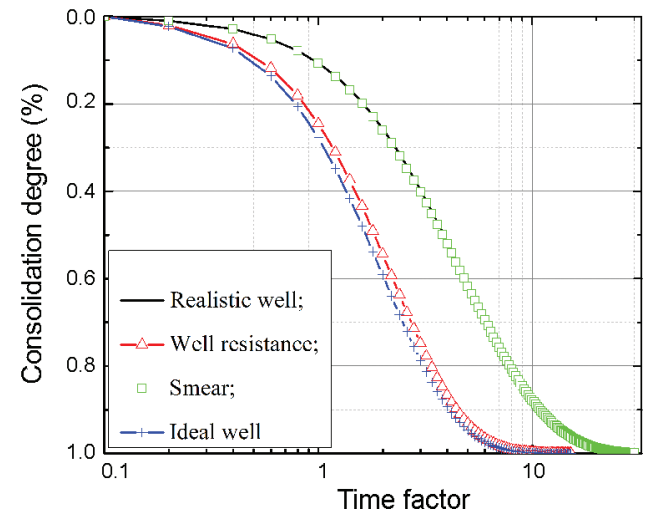

Figure 11. Influence of the smear effect and the well resistance on the consolidation degree

pervious; in this case the consolidation rate may be overestimated, because the drainage capacity may be reduced by blocking of porosity. But this limitation could be compensated by the theory of consolidation under the continuous drainage boundary, and a more precise prediction of the consolidation degree and settlements could be received.

\section{Experimental validation of the model}

The validity of the analytical solution is verified by degradation as described in section 4 . And the practicability of this model is verified based on the experimental results of Parsa-Pajouh, Fatahi, and Khabbaz (2016) in this section. This experiment was conducted by a large-scale Rowe cell, and the experimental model includes the sand well, smear zone and undisturbed area whose parameters shown in Table 2.

During the experiment, filter paper and porous plate were placed on the surface of the soil sample, and the bottom was impervious. The data of settlements and the variation of excess pore water pressure during consolidation were obtained by four stages of loading $(20,50,100$, and $200 \mathrm{kPa}$ ). The validation process is divided into two steps. (1) According to Table 2 and the settlement curves of experiment, the parameter $b$ in Eqn (34) is fitted. The result is shown in Figure 12. (2) According to Eqn (30), the excess water pressure curves at $z=0.11 \mathrm{~mm}$ and $r=0.125 \mathrm{~mm}$ are compared with the curve of Parsa-Pajouh, Fatahi, and Khabbaz (2016) to verify the accuracy and practicability of the model. The results are shown in Figure 13. It is worth noting that the ground under each stage of load is regarded as completely consolidated based on the continuous drainage boundary. There are two vertical pink dashed lines in Figure 12, which stand for a particular time, close to the final settlement.

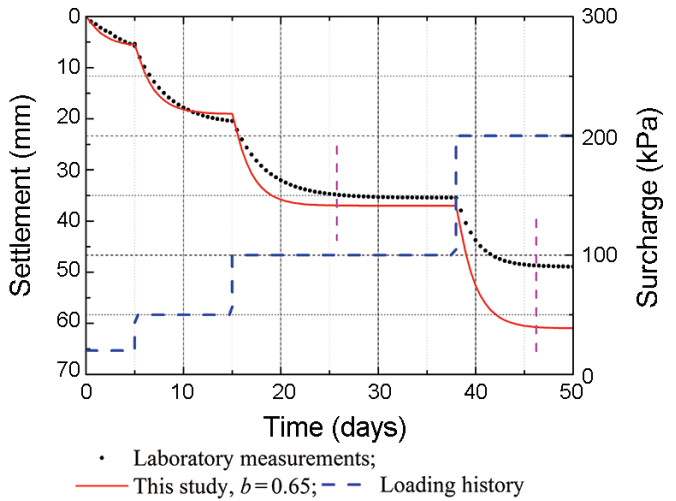

Figure 12. Comparison curves of settlements versus time between experiment and calculation

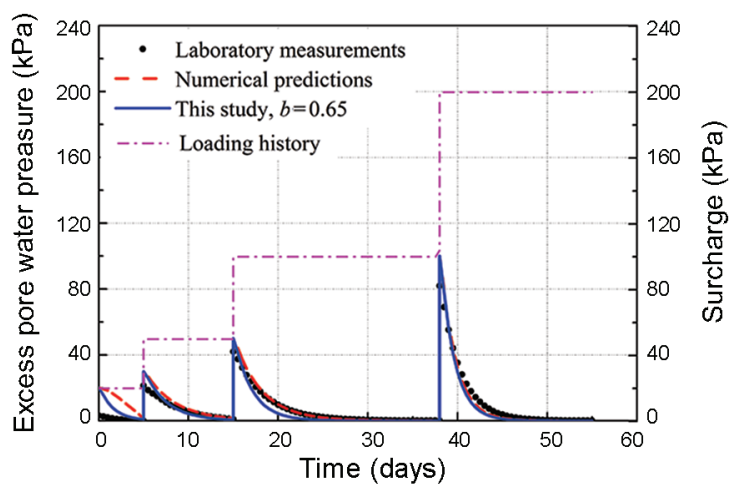

Figure 13. Variation of excess pore water pressure versus time obtained by different methods

Figure 12 shows that, when $b=0.65$, settlements obtained from the experiment is close to the results of calculation under the first load. The experimental settlement at the end of secondary load is slightly larger than the calculated result. This is because the settlement under the first load does not end when the second load is applied in the experiment. However, in the calculation of this model, it is assumed that a sufficient settlement caused by the present load has been achieved before applying the next load. Under the third and fourth load, there is a disparity in the final settlement. We suppose that the assumption in this study that the coefficients of compressibility and permeability remain constant during consolidation may be responsible for this phenomenon. In the experiment, the permeability coefficient and compression coefficient may change under the previous pressure, and the friction of the shaft wall may offset some of the stress. Although the gap of the final settlement is increasing, the time to reach the final settlement is similar under the last two loads. This is

Table 2. Physical parameters of the experiment

\begin{tabular}{|c|c|c|c|c|c|c|c|c|}
\hline \multirow{2}{*}{$\begin{array}{c}\text { Depth } \\
H / \mathrm{m}\end{array}$} & \multicolumn{3}{|c|}{ Permeability coefficient $k /(\mathrm{m} / \mathrm{d})$} & \multirow{2}{*}{$E_{s} / \mathrm{kPa}$} & \multicolumn{3}{|c|}{ Radius $r / \mathrm{m}$} \\
\cline { 2 - 6 } \cline { 7 - 9 } & $k_{h}$ & $k_{v}$ & $k_{s}$ & $k_{w}$ & & $r_{e}$ & $r_{s}$ & $r_{w}$ \\
\hline 0.2 & $1.56 \times 10^{-3}$ & $1.56 \times 10^{-3}$ & $3.89 \times 10^{-4}$ & 388.8 & 667 & 0.125 & 0.033 & 0.011 \\
\hline
\end{tabular}


because the interface parameter $b$ represents the drainage capacity of the top surface, which only affects the consolidation speed, but not the final settlement. The difference of settlement between the experiment and calculation is caused by ignoring the variation of compression coefficient and permeability coefficient. Therefore, we believe that the calculation results from the consolidation theory under continuous drainage boundary at $b=0.65$ are acceptable.

Figure 13 illustrates the variation of excess pore water pressure versus time, obtained by experiment, simulation and calculation. The dissipation rates by three methods are different under the first load. This is because the initial excess pore water pressure must be equal to the applied load, either in simulation or in model calculation. However, the excess pore water pressure in the experiment is smaller than the load; friction on the inner wall of the instrument may explain this phenomenon. Under the second load, results of calculation and simulation are close to the laboratorial measurements. The dissipation of the excess pore water pressure calculated by the model is relatively faster under the third and fourth load than the simulation and experimental results, but the difference among them is small. Therefore, we believe the consolidation model under continuous drainage boundary is reliable.

\section{Conclusions}

For the contradiction between the boundary condition and the initial condition in the traditional consolidation theory of the vertical drain under instantaneous constant load, continuous drainage boundary condition is applied to solve the vertical drain consolidation equation. The analytical solution of $3 \mathrm{D}$ consolidation of vertical drain is obtained and compared with the existing analytical solution. The following conclusions were obtained.

1. Continuous boundary condition can fully satisfy the initial condition. Degradation and comparison demonstrated that the analytical solution under the continuous drainage boundary condition is correct. Any status between the entire boundary process from complete pervious to impervious can be realized by changing the value of the interface parameter $b$. This process compensates for the limitation of the traditional theory which can only express the extreme state of complete drainage or no drainage.

2. Excess pore water pressure in the foundation under the continuous drainage boundary condition is not only related with the position and consolidation time, but is also influenced by the interface parameter $b$. The closer it is to the foundation top surface and the vertical drain center, the faster the excess pore pressure dissipates. The longer the consolidation time, the smaller the excess pore water pressure. In addition, larger value of $b$ causes faster dissipating of the excess pore water pressure.

3. In contrast with the traditional theory under the continuous drainage boundary condition within a certain period, excess pore water pressure exists at the foundation top surface. The excess pore water pressure on the top surface gradually dissipates with increased consolidation time.

4. In the vertical drain foundation, the vertical drainage capacity also has a significant influence and cannot be ignored although it is mainly based on radial drainage. The permeability coefficient of the smear area, the smear area range and the well resistance also have a significant effect on the average consolidation degree of the vertical drain. The disturbance to the well wall should therefore be minimized in construction.

\section{Funding}

This work was supported by the National Natural Science Foundation of China under Grant [number 51678547]; National Natural Science Foundation of China under Grant [number 51322807]; and MOE Engineering Research Center of Rock-Soil Drilling \& Excavation and Protection under Grant [number 201402].

\section{Disclosure statement}

Authors do not have any competing financial, professional, or personal interests from other parties.

\section{References}

Azari, B., Fatahi, B., \& Khabbaz, H. (2016). Assessment of the elastic-viscoplastic behavior of soft soils improved with vertical drains capturing reduced shear strength of a disturbed zone. International Journal of Geomechanics, 16(1), B401400115. https://doi.org/10.1061/(ASCE)GM.1943-5622.0000448

Barron, R. A. (1948). Consolidation of fine-grained soils by drain wells. Transactions of American Society of Civil Engineers, 74(6), 718-742.

Basack, S., \& Nimbalkar, S. (2017). Free strain analysis of the performance of vertical drains for soft soil improvement. Geomechanics and Engineering, 13(6), 963-975.

Cai, Y. Q., Liang, X., Zheng, Z. F., \& Pan, X. D. (2003). Onedimensional consolidation of viscoelastic soil layer with semi-permeable boundaries under cycle loadings. China Civil Engineering Journal, 36(8), 86-90. https://doi.org/10.15951/j.tmgcxb.2003.08.017

Carrillo, N. (1942). Simple two and three dimensional case in the theory of consolidation of soils. Studies in Applied Mathematics, 21(1-4), 1-5. https://doi.org/10.1002/sapm19422111

Deng, Y. B., Xie, K. H., Lu, M. M., Tao, H. B., \& Liu, G. B. (2013). Consolidation by prefabricated vertical drains considering the time dependent well resistance. Geotextiles and Geomembranes, 36, 20-26. https://doi.org/10.1016/j.geotexmem.2012.10.003

Geng, X., \& Yu, H. S. (2017). A large-strain radial consolidation theory for soft clays improved by vertical drains. Geotechnique, 67(11), 1020-1028. https://doi.org/10.1680/jgeot.15.T.013

Gibson, R. E. (1958). The progress of consolidation in a clay layer increasing in thickness with time. Geotechnique, 8(4), 171183. https://doi.org/10.1680/geot.1958.8.4.171 
Hansbo, S., Jamiolkowski M., \& Kok, L. (1981). Consolidation by vertical drains. Geotechnique, 31(1), 45-66. https://doi.org/10.1680/geot.1981.31.1.45

Ho, L., Fatahi, B., \& Khabbaz, H. (2015). A closed form analytical solution for two-dimensional plane strain consolidation of unsaturated soil stratum. International Journal for Numerical and Analytical Methods in Geomechanics, 39(15), 1665-1692. https://doi.org/10.1002/nag.2369

Ho, L., Fatahi, B., \& Khabbaz, H. (2016). Analytical solution to axisymmetric consolidation in unsaturated soils with linearly depth-dependent initial conditions. Computers and Geotechnics, 74, 102-121. https://doi.org/10.1016/j.compgeo.2015.12.019

Hu, A. F., Xia, C. Q., Cui, J., Li, C. X., \& Xie, K. H. (2018). Nonlinear consolidation analysis of natural structured clays under time-dependent loading. International Journal of Geomechanics, 18(2), 1-16. https://doi.org/10.1061/(ASCE)GM.1943-5622.0001059

Indraratna, B., Rujikiatkamjorn, C., \& Sathananthan, I. (2005). Radial consolidation of clay using compressibility indices and varying horizontal permeability. Canadian Geotechnical Journal, 42(5), 1330-1341. https://doi.org/10.1139/T05-052

Karim, M. R., \& Oka, F. (2010). An automatic time increment selection scheme for simulation of elasto-viscoplastic consolidation of clayey soils. Geomechanics and Geoengineering, 5(3), 153-177. https://doi.org/10.1080/17486020903576226

Karlsson, M., Emdal, A., \& Dijkstra, J. (2016). Consequences of sample disturbance when predicting long-term settlements in soft clay. Canadian Geotechnical Journal, 53(12), 1965-1977. https://doi.org/10.1139/cgj-2016-0129

Kim, R., Hong, S. J., Lee, M. J., \& Lee, W. (2011). Time dependent well resistance factor of PVD. Marine Georesources and Geotechenology, 29(2), 131-144. https://doi.org/10.1080/1064119X.2010.525145

Li, C. X., Xu, C., \& Xie, K. H. (2017). Nonlinear consolidation of clayed soil considering non-Darcy flow and stress history. Rock and Soil Mechanics, 38(1), 91-100. https://doi.org/10.16285/j.rsm.2017.01.012

Lu, M. M., Wang, S. Y., \& Sloan, S. W. (2015). Nonlinear radial consolidation of vertical drains with coupled radial-vertical flow considering well resistance. Geotextiles and Geomembranes, 43(2), 182-189.

https://doi.org/10.1016/j.geotexmem.2014.12.001

Mei, G. X., Xia, J., \& Mei, L. (2011). Terzaghi's one-dimensional consolidation equation and its solution based on asymmetric continuous drainage boundary. Chinese Journal of Geotechnical Engineering, 33(1), 28-31.

Parsa-Pajouh, A., Fatahi, B., \& Khabbaz, H. (2016). Experimental and numerical investigations to evaluate two-simensional modeling of vertical drain-assisted preloading. International Journal of Geomechanics, 16(1), 1-14. https://doi.org/10.1061/(ASCE)GM.1943-5622.0000507

Parsa-Pajouh, A., Fatahi, B., Vincent, P., \& Khabbaz, H. (2014a). Trial embankment analysis to predict smear zone characteris- tics induced by prefabricated vertical strain installation. Geotechnical \& Geological Engineering, 32(5), 1187-1201. https://doi.org/10.1007/s10706-014-9789-9

Parsa-Pajouh, A., Fatahi, B., Vincent, P., \& Khabbaz, H. (2014b). Analyzing consolidation data to predict smear zone characteristics induced by vertical drain installation for soft soil improvement. Geomechanics and Engineering, 7(1), 105-131. https://doi.org/10.12989/gae.2014.7.1.105

Rujikiatkamjorn, C., \& Indraratna, B. (2009). Design procedure for vertical drains considering a linear variation of lateral permeability within the smear zone. Canadian Geotechnical Journal, 46(3), 270-280. https://doi.org/10.1139/T08-124

Sales, M. M., Prezzi, M., Salgado, R., Choi, Y. S., \& Lee, J. (2017). Load-settlement behaviour of model pile groups in sand under vertical load. Journal of Civil Engineering and Management, 23(8), 1148-1163. https://doi.org/10.3846/13923730.2017.1396559

Sun, J., Xie, X. Y., \& Xie, K. H. (2007). Analytical theory for consolidation of double-layered composite round under impeded boundaries. Journal of Zhejiang University (Engineering Science), 41(9), 1467-1471.

Taslimian, R., Noorzad, A., \& Javan, M. R. M. (2015). Numerical simulation of liquefaction in porous media using nonlinear fluid flow law. International Journal for Numerical and Analytical Methods in Geomechanics, 39(3), 229-250. https://doi.org/10.1002/nag.2297

Wang, L., Sun, D. A., Li, L. Z., Li, P. C., \& Xu, Y. F. (2017). Semianalytical solutions to one-dimensional consolidation for unsaturated soils with symmetric semi-permeable drainage boundary. Computers and Geotechnics, 89, 71-80. https://doi.org/10.1016/j.compgeo.2017.04.005

Wang, Z. F., Shen, S. L., Ho, C. E., \& Kim, Y. H. (2013). Investigation of field-installation effects of horizontal twin-jet grouting in Shanghai soft soil deposits. Canadian Geotechnical Journal, 50(3), 288-297. https://doi.org/10.1139/cgj-2012-0199

Xie, K. H., \& Zeng, G. X. (1989). Consolidation theories for drain wells under equal strain condition. Journal of Geotechnical Engineering, 11(2), 3-17.

Xie, K. H., Wang, K., \& Wang, Y. L. (2010). Analytical solution for one-dimensional consolidation of clayey soils with a threshold gradient. Computers and Geotechnics, 37(4), 487493. https://doi.org/10.1016/j.compgeo.2010.02.001

Yoshikuni, H., \& Nakanodo, H. (1974). Consolidation of soils by vertical drain wells with finite permeability. Soils and Foundations, 14(2), 35-46. https://doi.org/10.3208/sandf1972.14.2_35

Zhang, Y. G., Xie, K. H., \& Wang, Z. (2006). Consolidation analysis of composite ground improved by granular columns considering variation of permeability coefficient of soil. In ASCE GeoShanghai International Conference Special Publication, Ground Modification and Seismic Mitigation (GSP 152) (pp. 135-142). https://doi.org/10.1061/40864(196)19

Zhou, Y., \& Chai, J. C. (2017). Equivalent 'smear' effect due to non-uniform consolidation surrounding a PVD. Geotechnique, 67(5), 410-419. https://doi.org/10.1680/jgeot.16.P.087 